\title{
Improvement of workflow and processes to ease and enrich meaningful use of health information technology
}

This article was published in the following Dove Press journal:

Advances in Medical Education and Practice

6 November 2013

Number of times this article has been viewed

\section{Ranjit Singh' \\ Ashok Singh ${ }^{2}$ \\ Devan R Singh ${ }^{3}$ \\ Gurdev Singh'}

'Department of Family Medicine, UB Patient Safety Research Center, School of Medicine and Management, State University of NY at Buffalo, NY, USA; ${ }^{2}$ Niagara Family Medicine Associates, Niagara Falls, NY, USA; ${ }^{3}$ SaferPatients LLC, Lewiston, NY, USA

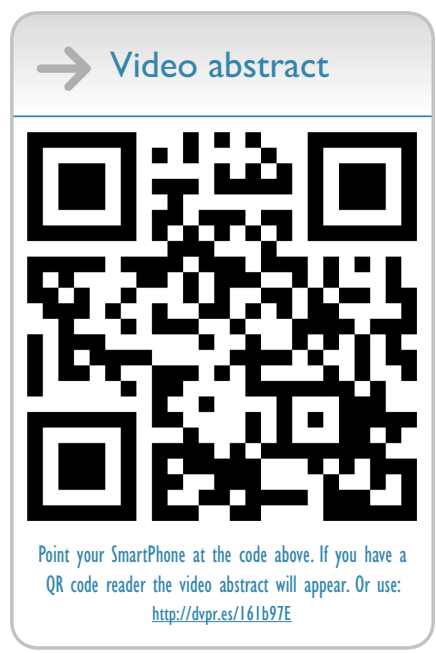

Correspondence: Gurdev Singh School of Medicine and Biomed. Sciences and School of Management, State University of NY at Buffalo, 77 Goodell Street, Buffalo, NY 14203, USA

$\mathrm{Tel}+\mathrm{I} 7168167274$

Fax +I 7162825545

Email gsingh4@buffalo.edu
Abstract: The introduction of health information technology (HIT) can have unexpected and unintended patient safety and/or quality consequences. This highly desirable but complex intervention requires workflow changes in order to be effective. Workflow is often cited by providers as the number one 'pain point'. Its redesign needs to be tailored to the organizational context, current workflow, HIT system being introduced, and the resources available. Primary care practices lack the required expertise and need external assistance. Unfortunately, the current methods of using esoteric charts or software are alien to health care workers and are, therefore, perceived to be barriers. Most importantly and ironically, these do not readily educate or enable staff to inculcate a common vision, ownership, and empowerment among all stakeholders. These attributes are necessary for creating highly reliable organizations. We present a tool that addresses US Accreditation Council for Graduate Medical (ACGME) competency requirements. Of the six competencies called for by the ACGME, the two that this tool particularly addresses are 'system-based practice' and 'practice-based learning and continuing improvement'. This toolkit is founded on a systems engineering approach. It includes a motivational and orientation presentation, 128 magnetic pictorial and write-erase icons of 40 designs, dry-erase magnetic board, and five visual aids for reducing cognitive and emotive biases in staff. Pilot tests were carried out in practices in Western New York and Colorado, USA. In addition, the toolkit was presented at the 2011 North American Primary Care Research Group (NAPCRG) meeting and an Agency for Health Research and Quality (AHRQ) meeting in 2013 to solicit responses from attendees. It was also presented to the officers of the Office of the National Coordinator (ONC) for HIT. All qualitative feedback was extremely positive and enthusiastic. The respondents recommended that the toolkit be disseminated widely to improve staff education and training, leading to practice improvements.

Keywords: education, health, practice, quality, reliability, safety

\section{Introduction}

'Better Health, Better Health care, and Better Value' (3Bs) are societal, ethical, and fiscal imperatives. Whilst the World Health Organization is working towards declaring patient safety a basic human right, the alarming situation in the USA is that at least $200,000^{1,2}$ individuals are killed every year in outpatient settings alone. This is despite the fact that the USA spends about US\$3.2 trillion, one-sixth of its gross domestic product, on health care. Various studies estimate that the economic impact of harm to patients is more than US\$1 trillion annually. According to the US Centers for Disease Control and Prevention, patient harm is the third highest cause of healthrelated mortality, after heart disease and cancer. In May 2002, the 55th World Health Assembly adopted Resolution 55.18, which urged member states to pay the "closest 
possible attention" to "the problem of patient safety" and to establish and strengthen science-based systems necessary for improving patient safety and the quality of health care and reduce "appalling costs of unsafe health care" globally. It is a well established fact ${ }^{3}$ that, in any setting or industry, better management of work processes leads to improved value. Education and training of stakeholders in this management skill needs appropriate tools.

Electronic health records (EHR) are expected to radically transform health care. They are considered essential for health care delivery system reform. The Patient Protection and Affordable Care Act (PPACA) payment reform is built on the expectation that all providers will be information technology (IT) enabled. EHR are expected to deliver information exchange and reporting by placing providers 'online'. Understandably, there is a call in the USA for 'meaningful use' of health IT (HIT). ${ }^{4}$ Its three primary components are as follows:

- Certified EHR.

- Electronic health information exchange.

- Quality reporting.

This will subsequently lead to the $3 \mathrm{Bs}$, with particular attention to 'better' safety-based quality health care. Any reduction in this harm is bound to cause a cascading reduction in mortality due to disease-related causes. As Paul O'Neill ${ }^{3}$ (former Secretary of the US Treasury and Chief Executive Officer of Alcoa) observed: "a safe organization is a costeffective quality organization."

While having the potential to enhance the $3 \mathrm{Bs}$, the implementation of HIT also results in unanticipated and undesirable consequences ${ }^{5}$ that challenge the reliability of health care organizations. ${ }^{6}$ Examples, as listed by the US Federal Agency for Health Research and Quality (AHRQ), ${ }^{7-10}$ are as follows:

- More work for clinicians.

- Unfavorable workflow changes.

- Continuing demand for system changes.

- Conflicts between electronic and paper-based systems.

- Negative user emotions.

- Generation of new kinds of errors.

- Changes in organizational power structure (in the context of this paper, 'organization context' is how an organization is structured and the way it operates. The 'organization power structure' refers to hierarchy wherein the closer one is to the top, the more power one is perceived to have. A flat organization promotes teamwork).

- Overdependence on technology.
All the above are related directly and indirectly to the perturbations caused by implementation of EHR. Workflow is often cited as the number one 'pain point' by providers. ${ }^{11-13}$ The term 'workflow' is used to describe interactions between all the numerous tasks, procedural steps in the processes of health care, staff and patients involved, and resources and equipment needed in each step. Workflow management focuses on processes of care required for efficient and high quality of care. This management must include interactions with other settings so as to ensure continuity of patient care. Its redesign needs to be tailored to the practice context, current workflow, the systems being introduced, and the resources available, among other factors. In other words, it must acknowledge and respect the uniqueness of each setting.

It is important to state that practice structure and organization, based on team resource management, can have very positive effects on the safety-based quality of patient care as well as satisfaction of all stakeholders. ${ }^{14-16}$ Team resource management in health care, as compared with crew resource management in aviation, refers to the education and training in proven methods for teamwork, leading to mutual respect, trust, collaboration, cooperation, and situational awareness. There is ample evidence ${ }^{3,14,17}$ that these can yield greater cost effectiveness without the unintended, undesirable, and unexpected effects of top-down incentive schemes. Tools and aids are needed to educate stakeholders and help them inculcate greater common vision, ownership, and empowerment among all stakeholders ${ }^{15,16}$ in any organization for continuing improvement.

\section{Objective of this work}

A large number of computer programs ${ }^{18}$ are available for workflow/process design and some of the good ones are open access and free. ${ }^{19}$ Our objective was to develop a self-contained workflow toolkit that uses 'universal visual language' and recognizes that most practices lack the required expertise and often need external assistance because the current methods (using esoteric charts or various software packages ${ }^{11}$ that require long and steep learning curves) are alien to health care workers and are, therefore, perceived to be barriers. Most importantly, their use does not readily help inculcate common vision, ownership, and empowerment among all stakeholders, and may even create disorder (increase in entropy). This calls for a tool that does not add to the extra burden of HIT introduction and implementation but rather aids and enriches it. Our primary objective was to educate staff by creating an intuitive pictorial tool for assessing the current and continuing redesigns 
of future workflows for achieving staff comfort, efficiency, communication, organization, productivity, effectiveness, safety, and satisfaction of patients and staff, all without having to seek outside help.

\section{Principles behind the toolkit design}

Workflow and processes are seen by the authors as flow of information, knowledge, decisions, humans (especially patients), and various objects in the four dimensions of office space and time. A user-friendly tool is required for educating all staff to understand and improve workflow and processes. Toolkit design is, therefore, founded on 'improvement science' (systems engineering that is inclusive of its human factor component). Unlike the current esoteric icons used for process design (or maps) that often use 'unified modeling language' that is alien to health care workers and patients (Figure 1) our design uses the universal language of pictures (Figure 2) to create meaningful process diagrams/maps (Figure 3) that can be readily understood by all members of the office teams. An opportunity to inculcate a common vision is availed. Worker and customer satisfaction are not compromised because it facilitates highly recommended participation from all in the organization, including patients. The design accommodates the uniqueness of each setting (ie, available resources) and the flexibility needs of health care organizations. ${ }^{20-24}$ This is in the spirit of US Accreditation Council for Graduate Medical Education (ACGME) competency requirements of medical residents. Of the six competencies called for by the ACGME, the two that this tool particularly addresses are 'system-based practice' and 'practice-based learning and continuing improvement'.

\section{Materials and methods}

The kit includes the following:

1. PowerPoint presentation for office team motivation and orientation; reviewing HIT issues and current esoteric methods and influence of workflow on safety followed by explanations of the who, what, where, when, why, and how of workflow, illustrated with example scenarios encouraging active input from participants.

2. Magnetic pictorial write-erase icons (128 'fridge magnet' type) (Figure 3) of 40 different designs including blank ones.

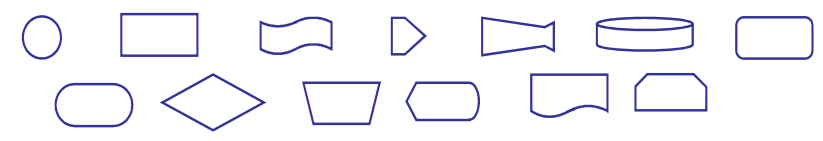

Figure I Examples of widely used esoteric icons.
3. Dry-erase magnetic board with write-erase pens.

4. Visual aids designed to reduce cognitive and emotive biases in staff and to help inculcate a shared vision. These aids, in turn, include:

- Collage of images of all the 40 icons.

- Lists of 'meaningful use' of HIT set of requirements.

- List of 16 likely process candidates for workflow assessment and redesign for value enhancement.

- Bar chart of relative frequencies of most commonly missing clinical information during primary care visits, eg, lab results.

- Four pages of the most commonly required activities in various domains of the office practice setting, including provider input, information input, inbound messages, testing process management, follow-up and checks, transition of patients, administration, and billing. A total of 85 activities are listed under these domains, with space to add other suitable activities.

The self-contained toolkit lends itself to a flexible approach to assessing current workflow processes, to explorations of alternative process patterns, and to a team-based choice of new improved processes. The toolkit aids inculcation of a common vision, ownership, and empowerment for all staff ${ }^{15,16}$ for continuing improvement in organizational processes. $^{25}$

\section{Findings}

The feedback from the participants was very positive and enthusiastic. The participants expressed the desirability of the toolkit being widely disseminated. We were informed that the kit was also successfully used by some respondents for improvements in processes outside the HIT context, on top of as a tool to design organizational structure. The following is a representation of the feedback from various users.

When I brought the toolkit to the [...] clinic, the Quality Improvement Manager became very excited and said, "I know just how we can use this" [...] The clinic immediately recognized the value of the toolkit to improve patient care, operational efficiency, and ensure that staff understood not only their own role in improving patient care but the larger picture of how people work together within the clinic.

In previous meetings, the physician champion of IT, and administrative staff had voiced concerns that there were gaps in the team-based approach to care and that the care team members were not always aware of their roles and responsibilities. Moreover, there was concern that nursing staff were not always following the standard 


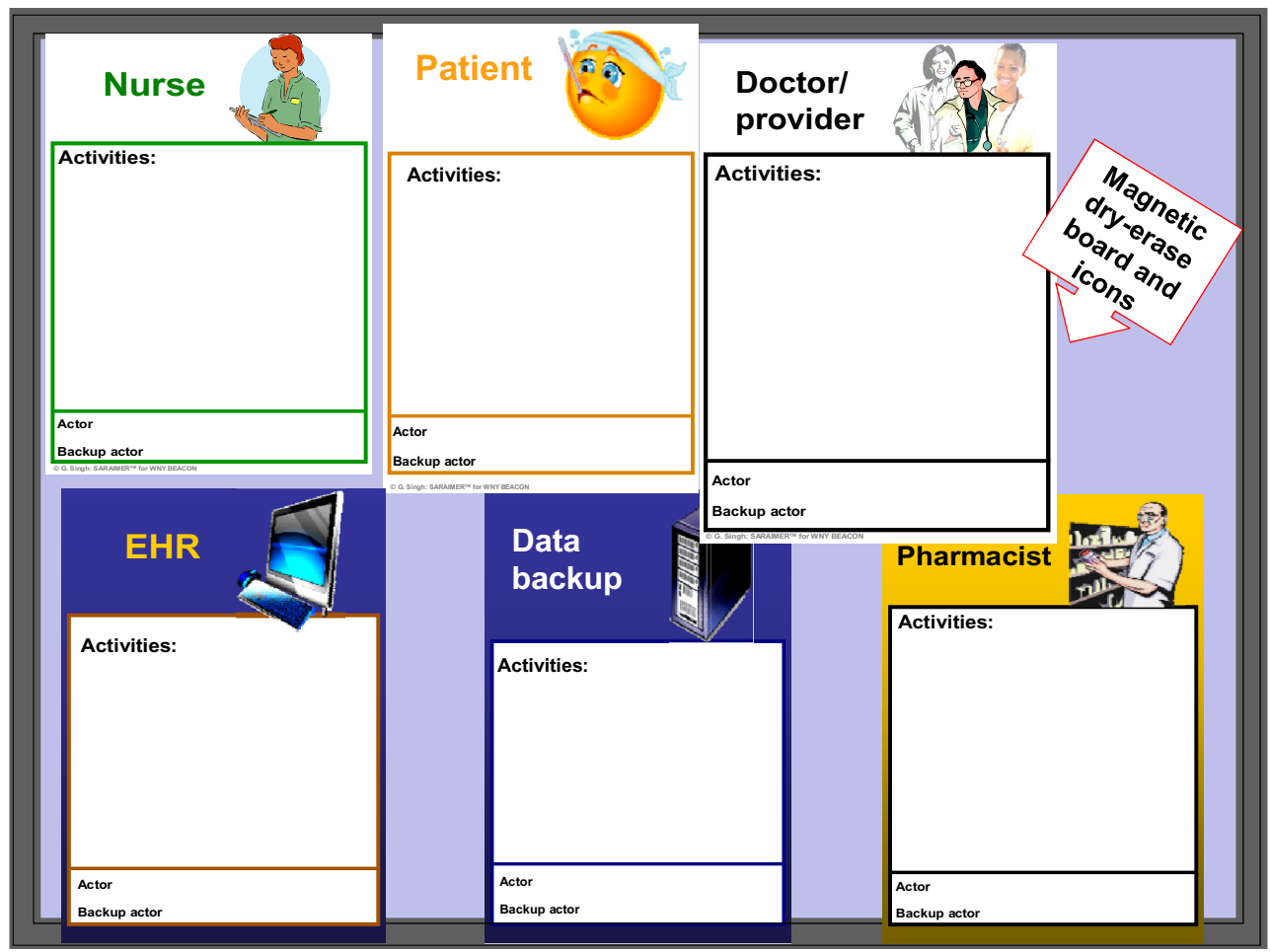

Figure 2 Six examples of pictorial icons proposed by the authors. Abbreviation: EHR, electronic health records.

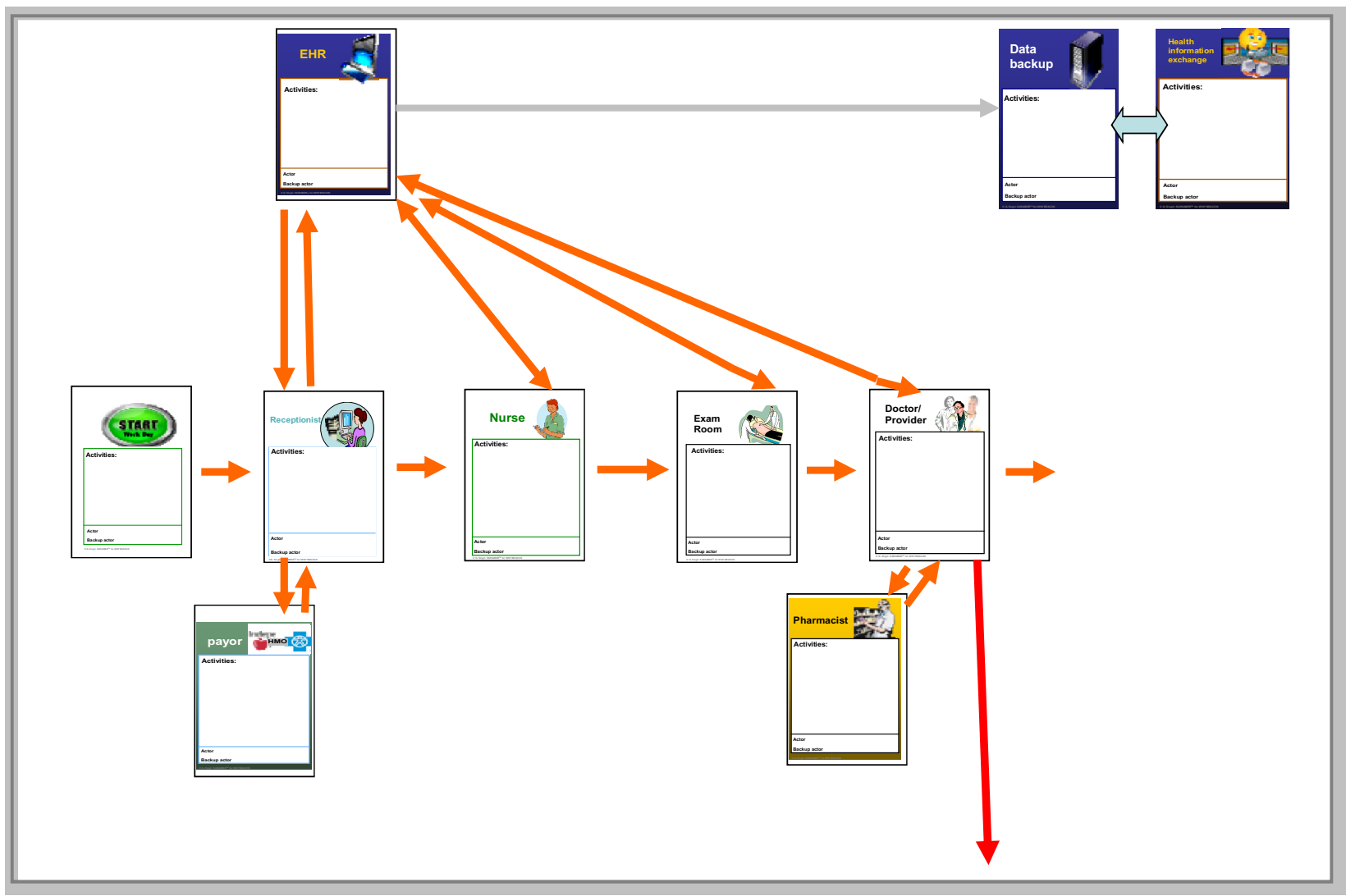

Figure 3 An example of a pictorial workflow diagram. Abbreviation: EHR, electronic health records. 
operating procedures that the clinic had tried to put in place to encourage chronic disease management, population management, and evidence-based guidelines.

Our emergency preparedness coordinator is eager to learn about the toolkit and how it can be used to map roles and workflows in response to emergency situations. In particular, she is interested in developing workflows and processes for how staff should respond to a patient presenting with an infectious disease.

You have created a really valuable tool and I am not surprised that it is generating so much interest.

The representative from the [...] Health Center of [...] started talking about how he uses the board often to illustrate workflows and review them with internal people as they discuss possible improvements. [...] that it has made a real difference in how he reviews processes within their practice.

The first thing that we [study participants] noticed, was that whenever we attended a quality improvement in the primary care arena presentation [nationally attended webinars and $\{\ldots\}$ conferences $\}$ the concept of presenting workflow challenges and other QI initiatives in a visual format was seeing more and more use.

When we [study participants] would mention the white board and magnet tools developed here in [...] our counterparts in other parts of the nation would want to know more.

We are extremely satisfied with the way in which we were able to capture the process flow with the board and magnetic icons. We could have done that by drawing on [a] board but there were many scenarios and the icons were moved many times to capture all possible scenarios. It was easy to understand visually, with the right images on each of the icons; also we listed out the activities too, in the space provided. After we captured each scenario, we took a snap shot of it and changed the icons to capture others. This not only saved time but also made sure that none of the steps in the process were missed. The idea was well appreciated by all the people in the meeting. Thank you for giving us an opportunity to work with the board, we shall take this valuable experience into our future endeavors too.

Oral presentations and demonstrations ${ }^{26}$ of this kit at North American Primary Care Research Group (NAPCRG) 2011, at an AHRQ meeting in 2013, and to the officers of the Office of the National Coordinator were very well received and numerous requests for acquiring it were received from the NAPCRG attendants, including five copies of the kit from a Chair at the Cleveland Clinic. Further dissemination and distribution of the toolkit to meet the need is called for.

\section{Discussion}

Medical education and training institutions have an important role to play in preparing health care workers to be aware of systemic issues and equipping them to engage in system improvement. A recent report ${ }^{27}$ of the UK Academy of Medical Royal Colleges places patient safety at the heart of good medical practice. The ACGME calls for six core competencies for all practitioners. The toolkit is designed to address these, but particularly the competencies of systembased practice and practice-based learning and improvement. Patient safety is seen as transcending these competencies.

Practice structure and organization based on team resource management can have very positive effects on the safety-based quality of patient care as well as the satisfaction of all stakeholders. ${ }^{14-16}$ There is ample evidence ${ }^{3,14,17}$ that these can yield greater cost effectiveness without the unintended, undesirable, and unexpected effects of top-down incentive schemes. Workflow and processes have profound influences on safety-based quality of care. Tools and aids are needed to educate stakeholders to help them inculcate greater common vision, ownership, and empowerment among all stakeholders ${ }^{15,16}$ in any organization for continuing improvement.

The primary strengths of the tool lie in its simplicity, its transferability to various clinical settings, its low cost, as well as its ability to serve as a training program to enhance ACGME competencies.

The limitation of this work arises from the fact that this is only a pilot study. The authors propose larger studies in the future after wide dissemination of this tool.

\section{Conclusion}

Better management of work processes is bound to lead to the $3 \mathrm{Bs}$ in health care. ${ }^{3}$ Outstanding success with the toolkit so far is a compelling reason for it to be made readily available. The participants in our tests recommended that the toolkit be disseminated widely to improve staff education and training, leading to practice improvements. This toolkit can also be used for improvements in processes outside the HIT context as well as for design of organizational structures.

\section{Acknowledgment}

The authors express gratitude to Renee Karl and Kate Abersole for their valuable help in carrying out pilot testing and assessing the efficacy of this tool. 


\section{Disclosure}

Ranjit Singh and Gurdev Singh are members of the World Health Organization Expert Panel for Patient Safety in Primary Care. Gurdev Singh is a Fellow of the Royal Society of Medicine (London) and is organizing further production of the tool for dissemination and distribution of the toolkit to meet the needs. The other authors report no conflicts of interest in this work.

\section{References}

1. Starfield B. Is US health really the best in the world? JAMA. 2000; 284:483-485.

2. Weingart SN, McLWilson R, Gibberd RW, Harrison B. Epidemiology of medical error. West J Med. 2000;172:390-393.

3. Meaningful use [webpage on the Internet]. Atlanta (GA): Centers for Disease Control and Prevention; 2012. Available from: http://www. cdc.gov/ehrmeaningfuluse/introduction.html. Accessed December 18, 2012.

4. Meaningful use [webpage on the Internet]. US Department of Health and Human Services, Office of the National Coordinator for Health Information Technology. Available from: http://healthit.hhs.gov/portal/ server.pt?open=512\&objID=2996\&mode=2. Accessed July 20, 2013.

5. Harrison MI, Koppel R, Bar-Lev S. Unintended consequences of information technologies in health care: an interactive sociotechnical analysis. J Am Med Inform Assoc. 2007;14(5):542-549.

6. Kushniruk A, Borycki E, Kuwata, et al. Predicting changes in workflow resulting from healthcare information systems: ensuring the safety of healthcare. Healthc Q. 2006;9 Spec No: 114-118.

7. Agency for Healthcare Research and Quality. Guide to Reducing Unintended Consequences of Electronic Health Records [webpage on the Internet]. Available from: http://www.healthit.gov/unintendedconsequences. Accessed October 4, 2013.

8. Carayan P, Karsh BT. Workflow Toolkit and Lessons in User Centered Design. Paper presented at: AHRQ Annual Health IT Grantee and Contractor Meeting; June 2-4, 2010; Washington, DC. Available from: http://healthit.ahrq.gov/sites/default/files/events/healthit_2010_ grantee_and_contractor_meeting/materials/plenary_sessions/p3_ carayon_karsh.pdf. Accessed June 28, 2013.

9. Ramaiah M, Subrahmanian E, Sriram RD, Lide BB. Workflow and electronic health records in small medical practices. Perspect Health Inf Manage. 2012;9:1d.

10. Niazkhani Z, van der Sijs H, Pirnejad H, Redekop WK, Aarts J. Same system, different outcomes: comparing the transitions from two paperbased systems to the same computerized physician order entry system. Int J Med Inform. 2009;78(3):170-181.

11. Agency for Healthcare Research and Quality. Workflow Assessment for Health IT Toolkit. Available from: http://healthit.ahrq.gov/portal/ server.pt/community/health_it_tools_and_resources/919/workflow_ assessment_for_health_it_toolkit/27865. Accessed May 23, 2013.

12. Baron RJ, Faben EL, Schiffman M, Wolf E. Electronic health records: just around the corner? Or over the cliff? Ann Intern Med. 2005;143(3):222-226.

Advances in Medical Education and Practice

\section{Publish your work in this journal}

Advances in Medical Education and Practice is an international, peerreviewed, open access journal that aims to present and publish research on Medical Education covering medical, dental, nursing and allied health care professional education. The journal covers undergraduate education, postgraduate training and continuing medical education
13. Fernandopulle R, Patel N. How the electronic health record did not measure up to the demands of our medical home practice. Health Aff (Millwood). 2010;29(4):622-628.

14. Gillam SJ. Pay for Performance in UK General Practice-The Ambiguous Impact of the Quality and Outcomes Framework. National Quality Measures Clearinghouse. Available from: http://qualitymeasures.ahrq.gov/ expert/printView.aspx?id=25658. Accessed July 3, 2013.

15. Singh R, Singh A, Anumba C, Singh G. Enhancing and measuring patient safety with an innovative web-based systems approach. Int $J$ AdvIntell Paradig. 2011;3(2):164-177.

16. Singh R, Singh A, Taylor JS, Rosenthal T, Singh S, Singh G. Building learning practices with self-empowered teams for improving patient safety. J Health Manage. 2006;8(1):91-118.

17. Grant S, Huby G, Watkins F, et al. The impact of pay-for-performance on professional boundaries in UK general practice: an ethnographic study. Sociol Health Illn. 2009;31(2):229-245.

18. Agiloft. Adaptive Business Automation Software [webpage on the Internet]. Available from: http://www.agiloft.com/business-processautomation-1.html?campaign=292135ou. Accessed October 2, 2013.

19. SoftwareForEnterprise. List of top open source PBM/workflow solution [webpage on the Internet]. Available from: http://www. softwareforenterprise.us/2009/03/13/list-of-top-open-source-bpmworkflow-solution/. Accessed July 3, 2013.

20. van der Aalst WMP, terHofstede AHM. YAWL: yet another workflow language. Inf Sys. 2005;30(4):245-275.

21. Greiner U, Ramsch J, Heller B. Adaptive guideline-based treatment workflows with AdaptFlow. In: Proceedings of the Symposium on Computerized Guidelines and Protocols; April 13-14, 2004; Prague. Amsterdam: IOS Press, Amsterdam. 113-117.

22. Han M, Thiery T, Song X. Managing exceptions in the medical workflow systems. In: Proceedings of the 28th International Conference on Software Engineering; May 20-28, 2006; Shanghai. New York: ACM; 2006:741-750.

23. Schonenberg MH, Mans RS, Russell NC, Mulyar NA, van der Aalst. Process flexibility: a survey of contemporary approaches. In: Dietz JLG, et al, editors. CIAO 2008. LNBIP, Vol 10, Springer, Heidelberg. 16-30.

24. Reijers HA, Russell N, van der Geer S, Krekels GAM. Workflow for healthcare: amethodology for realizing flexible medical treatment processes. In: Rinderle-Ma S, Sadiq S, Leymann F, editors. Business Process Management Workshops: BPM 2009 International Workshops, Ulm, Germany, September 7, 2009. Revised papers. Heidelberg: Springer; 2010:593-604.

25. Berwick DM. The question of improvement. JAMA. 2012;307(19): 2093-2094.

26. Singh A, Singh R, Anderson D, et al. An Innovative Interactive Workflow Re-design Toolkit for Primary Care Offices. Buffalo (NY): NAPCRG; 2011. Available from: http://www.fmdrl.org/index.cfm?event=c.begin BrowseD\&clearSelections=1\&criteria=Singh. Accessed September 2, 2013.

27. Guidance on Return to Practice [webpage on the Internet]. London: Academy of Medical Royal Colleges; 2012. Available from: http:// www.aomrc.org.uk/about-us/news/item/academy.html. Accessed October 4, 2013.

\footnotetext{
Submit your manuscript here: http://www.dovepress.com/advances-in-medical-education-and-practice-journal
}

including emerging trends and innovative models linking education, research, and health care services. The manuscript management system is completely online and includes a very quick and fair peer-review system. Visit http://www.dovepress.com/testimonials.php to read real quotes from published authors. 